\title{
GP funding formula masks major inequalities for practices in deprived areas
}

\author{
Kambiz Boomla clinical senior lecturer, Sally Hull reader in primary care development, John Robson \\ reader in primary care research and development
}

Queen Mary University of London, London E1 2AB, UK

Appleby reminds us that general practice funding has fallen to $8 \%$ of total NHS spending. ${ }^{1}$ But his analysis masks the important point that differing population needs greatly affect practice workload.

The 2004 Carr-Hill funding formula had the laudable aim of allocating funds to reflect the workload requirements of each practice population. Reliable data on the workload implications of social deprivation were unavailable, and the resulting formula did not redress the health burden of inequality, as shown by Marmot and others. ${ }^{23}$ Instead some practices required funding support through the minimum practice income guarantee (MPIG) to offset closures. In 2014, as the MPIG is phased out, the underlying problems with the equitable distribution of the global sum are again apparent. ${ }^{4}$

Appleby reports a dearth of information on activity and consultation rates in general practice. ${ }^{1}$ But this information is not hard to generate. ${ }^{5}$ We examined annual consultation rates for one million GP registered people in east London, broken down by national quintiles of index of multiple deprivation (IMD). We found that someone aged 50 in the most deprived quintile consults at the same rate as someone aged 70 in the least deprived quintile (figure $\downarrow$ ). This reflects Marmot's findings of an 18 year gap in disability-free life expectancy. ${ }^{2}$

These additional consultations are not trivial. Consultations that include common blood tests show a similar distribution by deprivation, indicating complexity.
We then recalculated the age-sex workload element in Carr-Hill by weighting the population by the observed consultation rates in each deprivation quintile. For Tower Hamlets, one of the top five deprived boroughs in England, we estimated that a fair formula that allowed for the additional workload would provide $33 \%$ more funding. If this were implemented the need for MPIG would disappear.

We are on the cusp of a second attempt at resource redistribution in primary care. We have shown that it is possible to measure the effect of deprivation on consultation rates. If the rhetoric of reducing health inequalities is to be meaningful for general practice, calibration of the funding formula for deprivation is an essential first step.

Competing interests: We are all GPs based in Tower Hamlets. Full response at: www.bmj.com/content/349/bmj.g6814/rr/808723.

Appleby J. Is general practice in trouble? BMJ 2014;349:g6814. (27 November.) Marmot M, Bell R. Fair society, healthy lives. Public Health 2012;126(suppl 1):S4-10. Barnett K, Mercer SW, Norbury M, Watt G, Wyke S, Guthrie B. Epidemiology of multimorbidity and implications for health care, research, and medical education: a cross-sectional study. Lancet 2012;380:37-43.

4 NHS England. Impact of phasing out the minimum practice income guarantee: "outlier" GP practices. 2014. www.england.nhs.uk/wp-content/uploads/2014/02/gp-gms-practices. pdf.

5 BMA and NHS Employers. Review of the general medical services global sum formula. 2007 www.derbyshirelmc.org.uk/Guidance/Review\%20of\%20the\%20GMS\%20Global\% 20Sum\%20Formula.pdf. 


\section{Figure}

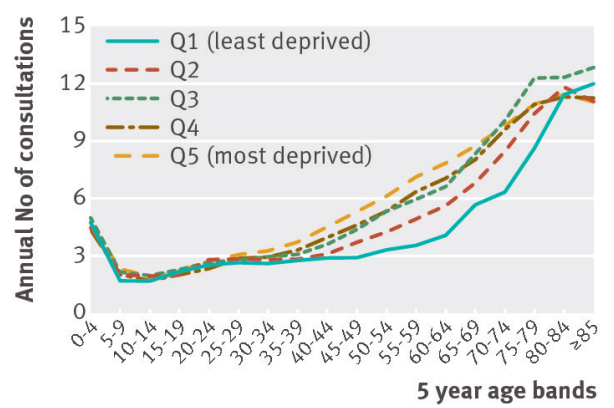

Consultation rates in east London by age and deprivation (quintiles of index of multiple deprivation for England) 